\title{
ON SPACE-TIME METRICS INDUCING THE RADIATION CONNECTION
}

\author{
G. Burdet, T. Papacostas ${ }^{1}$ and M. Perrin
}

\begin{abstract}
It is shown that Lorentzian manifolds giving rise to the radiation connection, i.e. such that the canonical connection induces a unique connection on an isotropic hypersurface, are of type D or conformally flat in Petrov classification, generalizing the Robinson-Bertotti electromagnetic universe with cosmological constant. Under an holonomy hypothesis it is deduced that the underlying space-time manifold is a direct product of two two-dimensional spaces, one of them being space-like, and the other one time-like.
\end{abstract}

June 1993

CPT-93/P.2926

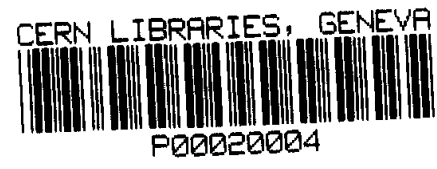

1 Physics Department, University of Crete, 714-09 Iraklion, Crete, Grece 


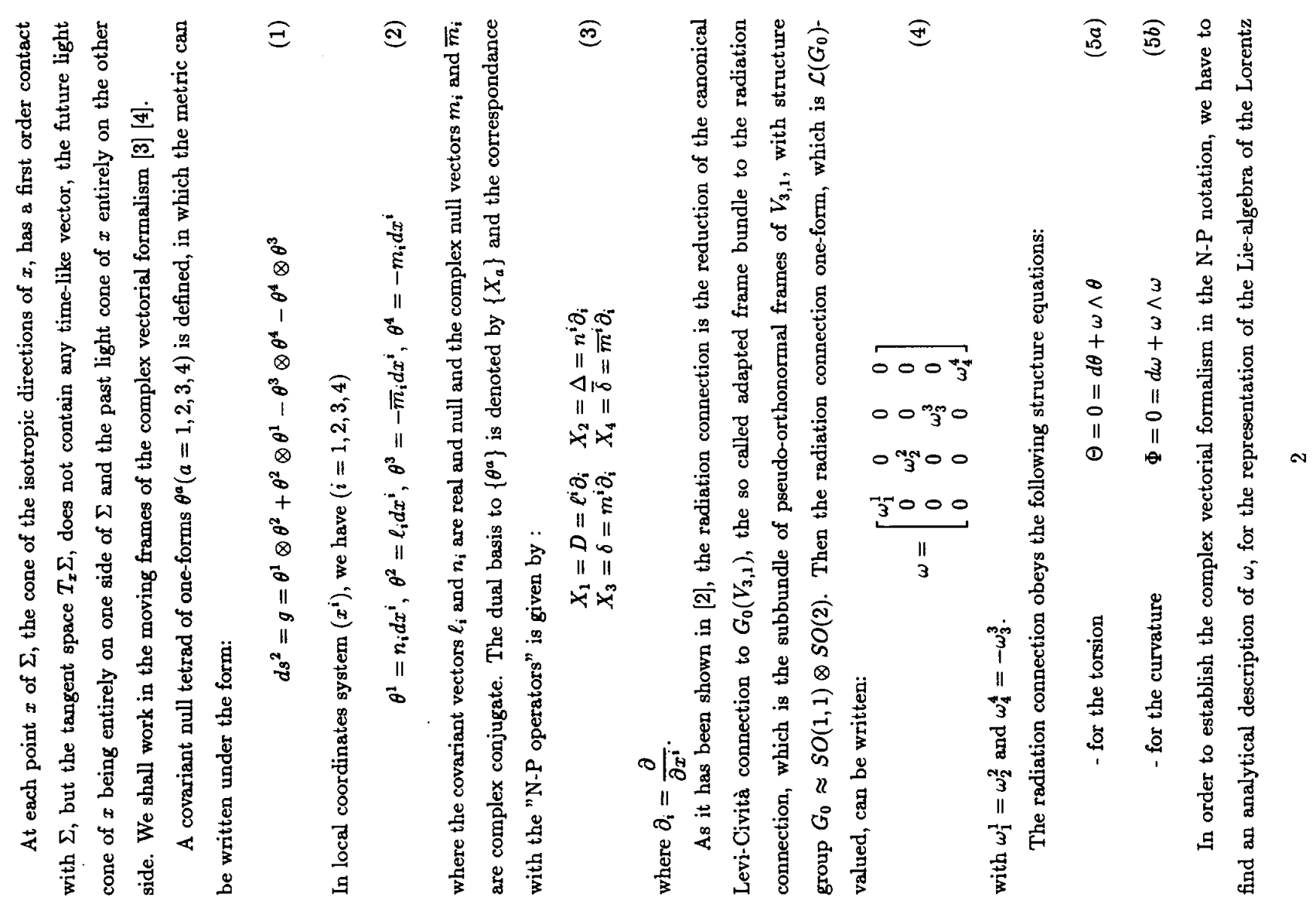

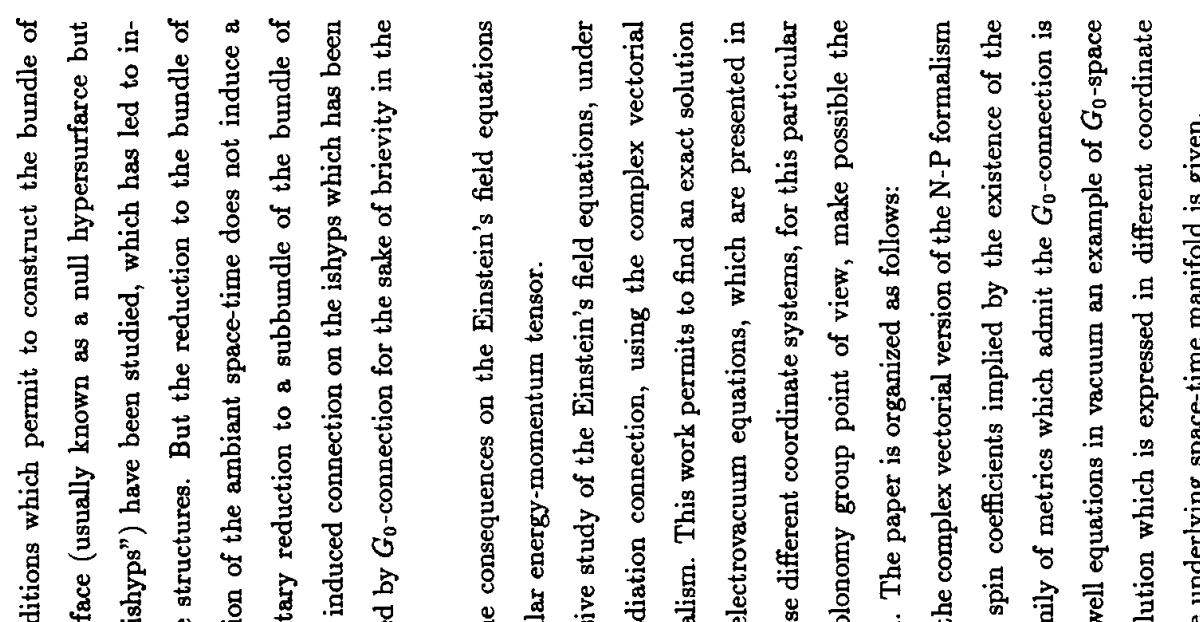
HIIn

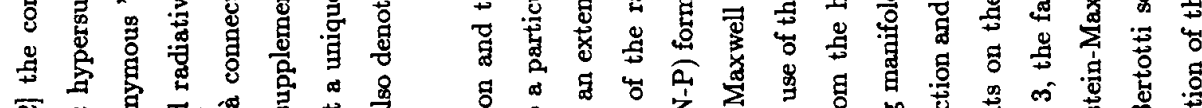

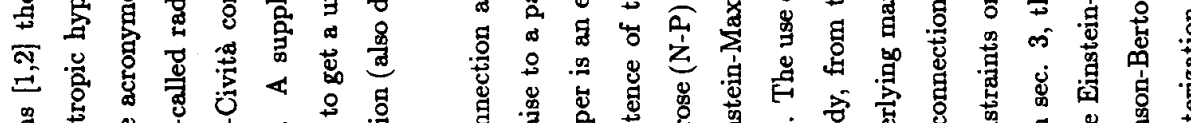

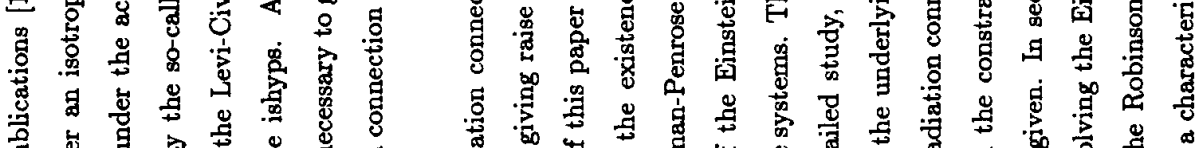

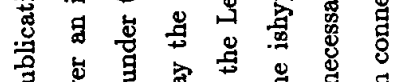

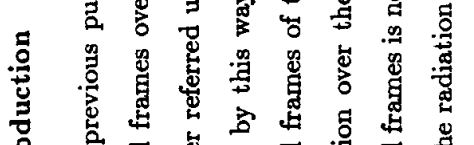

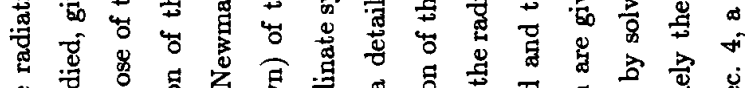

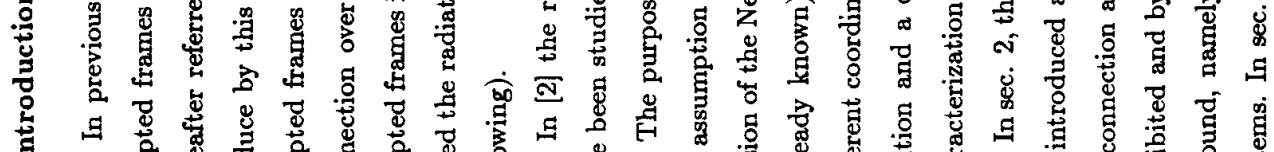

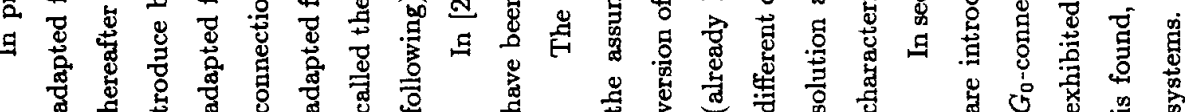

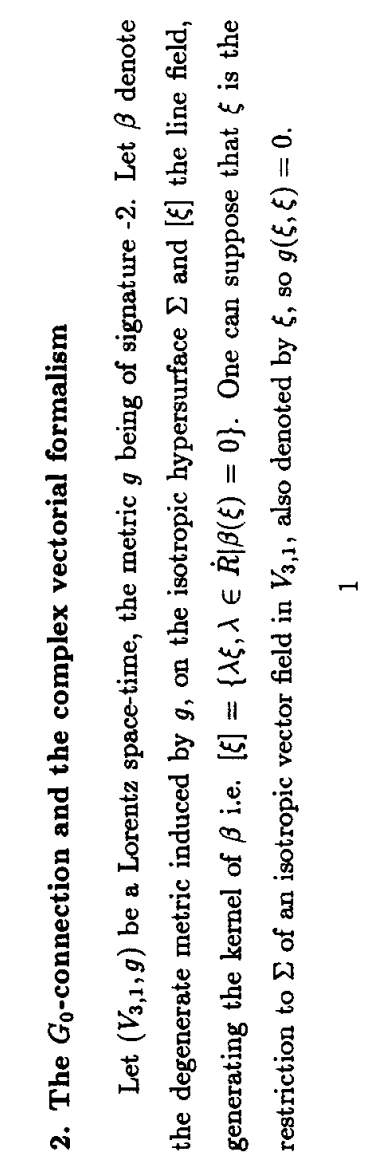




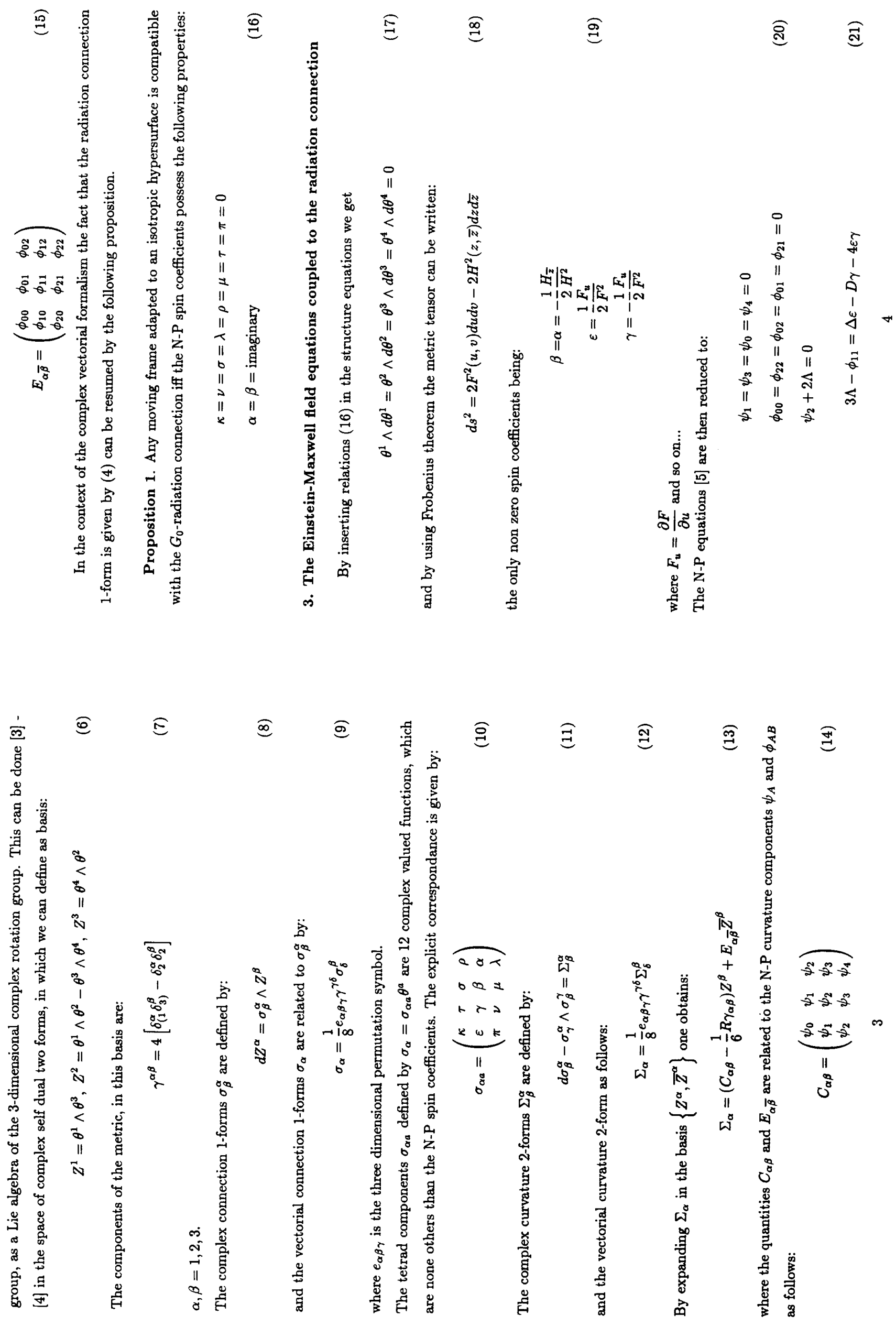




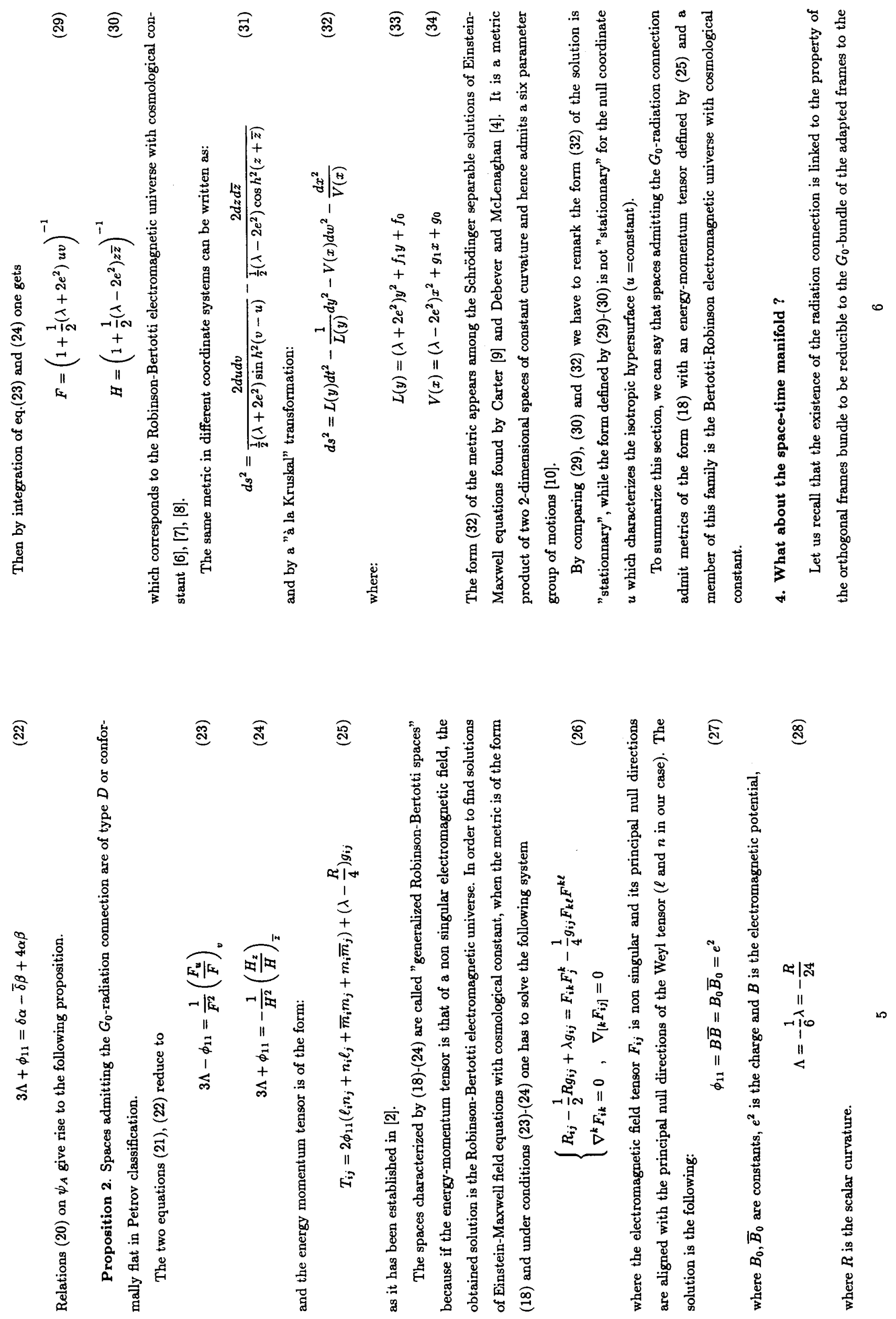




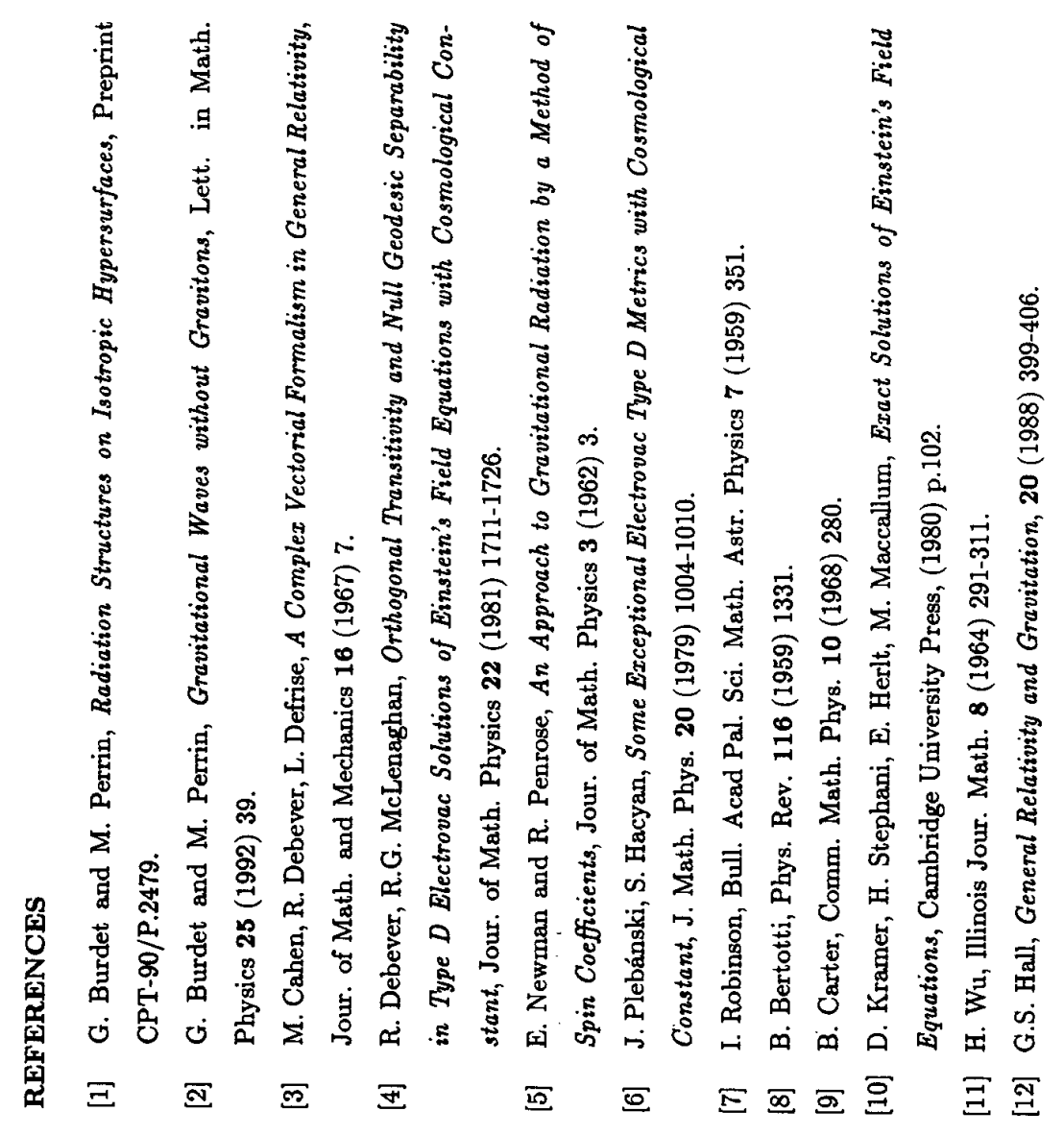

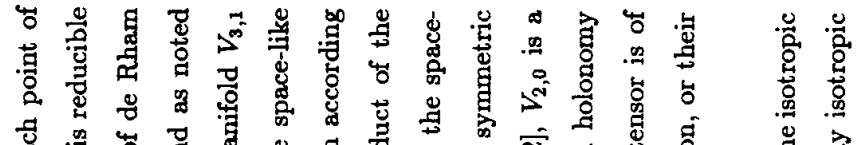

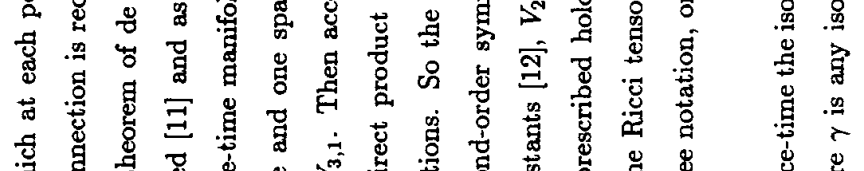

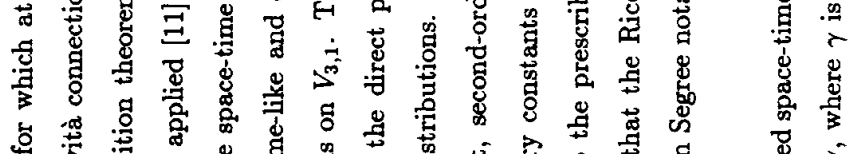

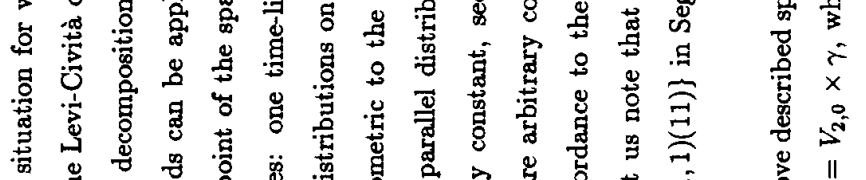

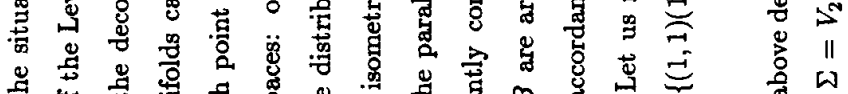

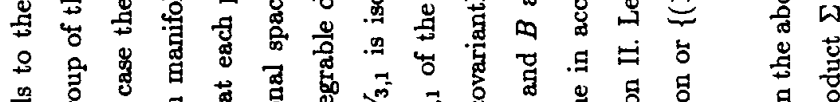

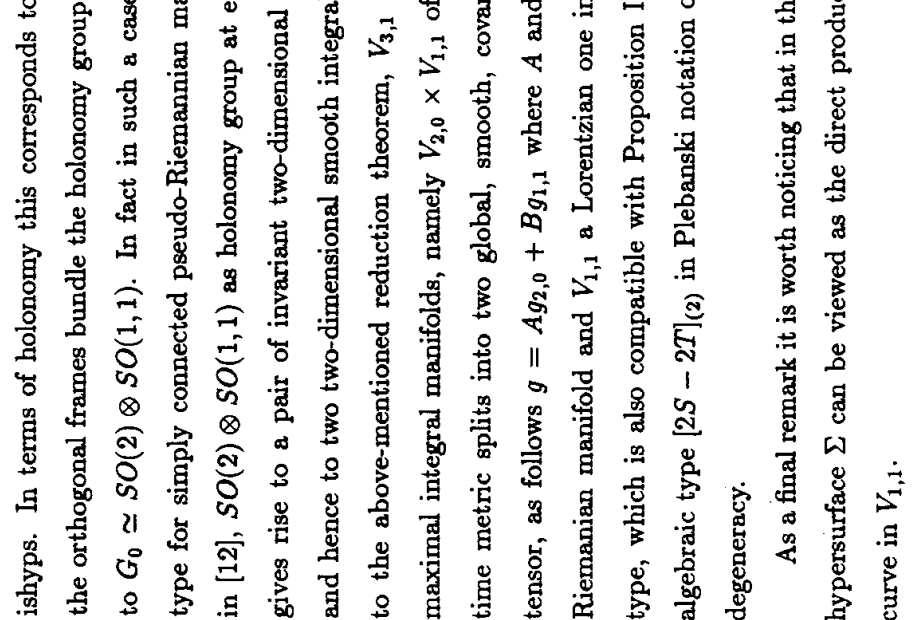

